\title{
GASTOS PÚBLICOS EM INFRAESTRUTURA E POBREZA: UMA ANÁLISE PARA O ESTADO DE MINAS GERAIS
}

\author{
Evandro Camargos Teixeira ${ }^{1}$ \\ Gabriel Henrique Rodrigues Corrêa ${ }^{2}$
}

RESUMO: O objetivo do presente trabalho é analisar a relação entre gastos públicos em infraestrutura e o nível de pobreza nos municípios do estado de Minas Gerais. Para a análise dessa relação, foi utilizado um modelo de dados em painel estático estimado por efeitos fixos. A proxy utilizada para representar a pobreza nesta pesquisa foi a taxa de famílias cadastradas no Cadastro Único com renda per capita até $1 / 2$ salário mínimo por 100.000 habitantes durante o período 2015-2017. Os resultados denotam relação inversa entre gastos públicos em infraestrutura e nível de pobreza nos municípios do estado de Minas Gerais no período supracitado, ou seja, para cada real destinado em gastos públicos em infraestrutura, há uma redução de 0,000407 na taxa de pobreza desses municípios.

Palavras-Chave: Infraestrutura, Pobreza; Dados em painel; Efeitos fixos.

ABSTRACT: The objective of this study is to analyze the relationship between public spending on infrastructure and the level of poverty in the municipalities of the state of Minas Gerais. For the analysis of this relationship, a static panel data model estimated by fixed effects was used. The proxy used to represent poverty in this research was the rate of families registered in the Unified Registry with per capita income up to $1 / 2$ minimum wage per 100,000 inhabitants during the period 20152017. The results show an inverse relationship between public spending on infrastructure and poverty levels in the municipalities of the state of Minas Gerais in the above-mentioned period, i.e., for each real allocated to public spending on infrastructure, there is a reduction of 0.000407 in the poverty rate of these municipalities.

Keywords: Infrastructure, Poverty; Panel data; Fixed effects.

\footnotetext{
1 Doutorado em Economia Aplicada (ESALQ/USP). Mestrado em Desenvolvimento Econômico (UFPR). Graduação em Economia (UFJF). Professor Associado I do Departamento de Economia da UFV. E-mail: evandro.teixeira@ufv.br.

${ }^{2}$ Graduando em economia (UFV). E-mail: gabriel.h.correa@ufv.br.
} 


\section{INTRODUÇÃO}

De acordo com o Banco Interamericano de Desenvolvimento - BID (2000), a infraestrutura apresenta-se como um conjunto de estruturas de engenharias e instalações que são o pilar necessário para o desenvolvimento de atividades produtivas de prestação de serviços, política, social e pessoal.

Maia (2015) a caracteriza como a base da economia, definindo a infraestrutura como responsável pelo desenvolvimento e geradora de externalidades positivas. Dividida em setores, elétrico, de comunicação e de transporte, a infraestrutura econômica é capaz de impactar de forma direta o mercado e, por conseguinte, toda a atividade econômica (FERREIRA, 2018).

A infraestrutura como um todo é tema recorrente em pautas de agendas governamentais, tanto em âmbito nacional quanto mundial. Ela representa uma espécie de "termômetro" do crescimento ou desenvolvimento de um qualquer Estado, ou seja, quando se tem um conjunto infraestrutural eficiente, quaisquer que sejam eles, de transporte, telecomunicação, saneamento, e etc.; o país, geralmente, apresenta bons indicadores econômicos e sociais.

A teoria econômica enfatiza a necessidade de o Estado prover determinados bens e serviços que não poderiam ser oferecidos de maneira socialmente ótima pelo setor privado, devido ao caráter não rival ou excludente de determinadas atividades e pela necessidade de elevada escala para diminuição dos custos em larga escala. Logo, a infraestrutura básica de uma economia deve ser, a priori, gerida pelo Estado, a exemplo de rodovias, ferrovias, portos, sistemas de água, esgoto, telecomunicações, dentre outros. (CAMPOS NETO; CONCEIÇÃO; ROMMINGER, 2015)

Aschauer (1989) vai ao encontro dessa ideia, ao afirmar que sendo uma externalidade fundamentalmente positiva em uma economia, afetando de forma favorável as transações econômicas e impulsionando a sua competitividade, a infraestrutura é comumente provida pelo Governo ou por empresas autorizadas para realizar esses serviços.

De acordo com Araújo, Campelo e Marinho (2013), historicamente, quase toda infraestrutura brasileira sempre foi de exclusiva responsabilidade do setor público. Contudo, com as parcerias realizadas entre o setor público e privado, a 
partir da década de 1990, aumentou consideravelmente a participação de empresas privadas nacionais e estrangeiras, através de privatizações de setores energéticos, de telecomunicações, e de malhas ferroviárias e rodoviárias. Apesar disso, ainda cabe ao Estado a função principal de prover os recursos infra estruturais, afirmam os autores.

Essa capacidade de impactar a economia concede a infraestrutura um poder de impacto que ultrapassa seus resultados diretos. Torrisi (2009) destaca que investimentos nesta área podem ser destinados tanto para infraestrutura econômica quanto social. A pobreza, por exemplo, pode ser impactada por esses recursos destinados às obras infraestruturais.

Nesse aspecto, o Brasil mantém historicamente uma tendência de grande desigualdade na distribuição de renda, o que acentua os já então elevados níveis de pobreza, tornando-se fundamental a solução desses problemas. Para se ter ideia, Cruz, Teixeira e Braga (2010) destacam que 22,18\% das famílias brasileiras apresentavam renda per capita menor que meio salário mínimo, sendo $16,36 \%$ delas em situação de pobreza e 5,82\% classificados como extremamente pobres.

Nesse aspecto, ao relacionar o papel da infraestrutura na redução da pobreza, destaca-se que mais acesso a serviços de infraestrutura também influenciam na realização dos chamados "Objetivos de Desenvolvimento do Milênio" (ODMs), com os quais o Brasil está comprometido (ARAÚJO, CAMPELO e MARINHO, 2013).

Nesse sentido, Araújo, Campelo e Marinho (2013) enfatizam a importância da infraestrutura no combate à pobreza. O mecanismo se materializa empiricamente, pois a infraestrutura é um componente vital no fomento ao crescimento econômico de um país, seja por ser um potencial gerador de empregos, ou pela sua complementariedade com as demais atividades econômicas que objetivam melhorar o desempenho da economia e amenizar a situação persistente de pobreza.

Levando em consideração a importância da temática, existem na literatura internacional diversos trabalhos que se empenharam em testar empiricamente 0 efeito da infraestrutura sobre a pobreza, como as contribuições de Jacoby (1988), Runsinarith (2008), Roy (2009), Ogun (2010), Seetanah, Remessur e Rojid (2009), Escobal (2001), dentre outros. 
Já em âmbito nacional, a literatura é mais restrita. Destacam-se os trabalhos de Cruz, Teixeira e Braga (2010), que enfatizam que o os dispêndios da União e dos estados em infraestrutura física e em capital humano elevam a produtividade do trabalho, emprego e os salários, bem como diminuem a pobreza; e Kageyama e Hoffmann (2006), que analisam pobreza e infraestrutura indiretamente, através de extensões de pobreza baseadas na renda, aspectos relativos ao bem estar ou ao desenvolvimento social.

Dadas as referidas definições e relações entre infraestrutura e pobreza, objetiva-se nesse trabalho avaliar os efeitos da infraestrutura sobre a pobreza no estado de Minas Gerais durante os anos de 2015 a 2017. A escolha do estado se deve à pluralidade que o mesmo apresenta, podendo ser uma boa proxy para 0 Brasil e contemplando em seu território características de todas as regiões brasileiras. Como destacado por Queiroz (2001):

"O estado de Minas Gerais é, provavelmente uma das regiões mais heterogêneas do país; coexistem no estado regiões dinâmicas, modernas e com indicadores socioeconômicos de alto nível com localidades atrasadas, estagnadas, que não oferecem a mínima condição de vida para a sua população". QUEIROZ (2001, pp.66)

O que se pretende nesse estudo é exatamente avaliar se os investimentos públicos em infraestrutura nos municípios do estado de Minas Gerais impactam sobre os seus respectivos níveis de pobreza, levando em consideração a heterogeneidade do estado evidenciada pelas disparidades infraestruturais.

Não foram encontrados estudos que relacionassem gastos públicos em infraestrutura e pobreza no estado de Minas Gerais. Logo, esta pesquisa pretende contribuir para a literatura e embasar novas políticas públicas de atenuação da pobreza através de gastos com infraestrutura no estado de Minas Gerais.

$\mathrm{O}$ estudo está dividido em mais quatro seções, além dessa introdução. $\mathrm{Na}$ próxima seção, são apresentados os aspectos teóricos e empíricos que versam o tema, seguidos da metodologia. Em seguida, os resultados são discutidos com posterior apresentação das considerações finais. 


\section{ASPECTOS TEÓRICOS E EMPÍRICOS}

Nesta seção, serão apresentados os trabalhos relevantes que tratam do tema desta pesquisa, destacando sua importância para a literatura, além de evidenciar alguns efeitos indiretos que a infraestrutura ocasiona na economia e que interferem no ciclo da pobreza.

O objetivo fundamental desse referencial é apresentar estudos com conclusões e resultados distintos sobre a mesma área de interesse, associando teorias e análises empíricas. Assim, serão apresentados trabalhos relevantes que relacionam infraestrutura e pobreza sob diferentes óticas, e que se servirão de respaldo ao referencial analítico dessa pesquisa.

A ideia geral que se propõe é a de que a provisão de infraestrutura adequada é peça chave para a redução da pobreza, uma vez que existe efeito direto no aumento da oferta de empregos e salários quando a economia cresce e torna-se mais eficiente e competitiva (ARAUJO, CAMPELO E MARINHO, 2010).

Dessa maneira, o aumento da provisão em infraestrutura diminuiria a pobreza na medida em que os ganhos em produtividade do trabalho fossem repassados para a renda dos mais pobres. A elevação da taxa de crescimento econômico, resultante do aumento do estoque em infraestrutura, também pode ser outro redutor da pobreza, uma vez que incentiva a geração de novos postos de trabalho na economia (ARAÚJO JÚNIOR, 2006).

A discussão em torno da relação entre infraestrutura e pobreza é objeto de pesquisa de diversos estudos na literatura econômica internacional. Jacoby (1998) salientou que a provisão de acesso rodoviário a mercados proporciona benefícios médios significativos para as famílias pobres. Entretanto, tais benefícios não foram elevados o suficiente para diminuir significativamente a desigualdade de renda no Nepal nos anos de 1995 e 1996.

Balisacan, Pernia e Asra (2002), através da utilização de dados em painel desagregados para 285 distritos da Indonésia no período de 1993 a 1999, também observaram efeito significativo de estradas sobre os rendimentos médios dos pobres através de crescimento econômico. Dercon e Krishan (1998), com dados coletados da Etiópia rural, em 1989, 1994 e 1995, detectaram que as famílias com maior 
capital humano e com melhor acesso a estradas apresentam menores taxas de pobreza.

Gibson e Rozelle (2003) tentaram compreender a eficácia do acesso a infraestrutura na redução da pobreza em Papua-Nova Guiné. Os autores examinaram a pobreza no país e procurou relacioná-la com a infraestrutura, chegando à conclusão de que a pobreza na localidade está associada àqueles que tem pouco acesso a serviços, mercados e transportes.

Runsinarith (2008) analisou a relação entre pobreza e infraestrutura em províncias quantílicas que fazem fronteira com o Cambodja. Os resultados encontrados pelo autor reforçam a ideia de que investimentos em telefonia, irrigação, eletricidade e estradas tiveram impacto positivo e estatisticamente significativos no consumo per capita, sendo o acesso a telefones celulares o item que mais impactou sobre a redução da pobreza, seguido pela eletricidade, estradas e irrigação.

Roy (2009), através da construção de dois índices de infraestrutura física (estradas, energia elétrica, projetos de irrigação, etc.) e social (hospitais, escolas, dentre outros), elaborados através do método de componentes principais, detectou forte correlação negativa entre o Índice de Pobreza Humana e a infraestrutura como um todo, para o período de 1970-2005 na Índia. Ogun (2010), com base em dados relativos ao período 1970-2005, confirmou o resultado encontrado por Roy (2009), salientando que o desenvolvimento em infraestrutura social e física reduziu significativamente a pobreza em áreas urbanas da Nigéria.

Seetanah, Ramessur e Rojid (2009) realizaram uma pesquisa sobre a relação entre infraestrutura e pobreza em alguns países em desenvolvimento. Os autores utilizaram dados pertencentes a 20 desses países durante o período de 1980-2005, confirmando a ideia de que existe na amostra uma conexão entre infraestrutura e alívio da pobreza, tomando como base a modelagem analisada.

Tomando como exemplo a América Latina, Bárcena et.al (2015) realizaram uma análise qualitativa da infraestrutura social na região. Os autores concluíram que mesmo com a melhoria observada nas últimas décadas através da maior cobertura de pessoas com acesso à saúde e educação, ainda é necessário um grande esforço para que estas infraestruturas sejam uma ferramenta para a diminuição da 
desigualdade e da pobreza através da qualidade do ensino e do atendimento à população.

Para o Peru, Escobal, Saavedra e Torero (2001) observaram efeitos significativos da infraestrutura (água potável, esgoto, eletricidade e telefonia) sobre a pobreza nos anos de 1985, 1991, 1994 e 2003. Os autores chegaram à conclusão de que a posse de telefone contribuiu em maior grau para reduzir a pobreza em áreas urbanas do que outros tipos de infraestrutura, apesar desse tipo de infraestrutura não surtir efeito significativo nas áreas rurais.

Rajkumar e Swaaroop (2008), utilizando-se de dados cross-section sobre gastos do governo com saúde e educação para os anos de 1990, 1997 e 2003 em 91 países, incluindo o Brasil, verificaram que existe causalidade reversa entre pobreza e infraestrutura em saúde.

Com relação à literatura nacional, existe uma restrição maior de trabalhos realizados que versam o tema. Medeiros e Ribeiro (2019) destacam a importância dos investimentos em infraestrutura para a redução da desigualdade de renda e pobreza. De acordo com os autores, a expansão de serviços básicos de infraestrutura resultaria em melhores perspectivas de emprego e salário, devido ao seu efeito positivo sobre a produtividade do trabalho em todos os setores da economia. A infraestrutura brasileira, entretanto, não é das mais favoráveis, o que gera gargalos ao crescimento econômico sustentado e aumento da produtividade no país.

Cruz Teixeira e Braga (2010), a partir de dados anuais para o Brasil no período de 1980 a 2007 e através de um sistema de equações simultâneas, comprovaram a eficiência das despesas públicas em educação e saúde, bem como em estradas e energia, quanto à melhoria da qualidade do capital humano e físico no país. Os autores concluíram também que os dispêndios da União e dos estados com educação e saúde (capital humano) e em capital físico (infraestrutura) são extremamente relevantes para gerar renda, aumentando a produtividade e tendo impacto positivo sobre os salários, o que permite a redução da pobreza.

Hiromoto (2018) analisou o efeito do gasto social dos governos federal, estadual e municipal sobre a pobreza no Brasil durante o período de 1988 a 2010. A fim de estimar o efeito do gasto público per capita sobre a proporção de pobres, a 
autora utilizou-se de uma base de dados composta por um painel de estados brasileiros durante dezenove anos, com um modelo econométrico de efeitos fixos, objetivando estimar o efeito das despesas estaduais sobre a proporção de pobres. Os resultados encontrados destacam os gastos em saúde e saneamento como os que apresentaram maior efeito redutor sobre a pobreza, em especial nas instâncias federal e municipal.

Araújo, Campelo e Marinho (2013) analisaram o impacto da infraestrutura sobre a pobreza no Brasil, através de um modelo dinâmico com dados em painel, encontrando efeito da infraestrutura sobre a redução da pobreza, cabendo evidenciar que os investimentos nessa área no país influenciam diretamente a trajetória temporal da pobreza no sentido de reverte-la.

Vide os estudos citados presentes na literatura econômica, pretende-se nesta pesquisa analisar o efeito dos gastos públicos em infraestrutura sobre a pobreza nos municípios do estado de Minas Gerais, podendo corroborar com teorias já expostas e auxiliar na formulação de políticas públicas ou tomadas de decisões que auxiliem no crescimento econômico do estado, através da diminuição da pobreza.

\section{METODOLOGIA}

Esta seção será dividida em duas subseções, sendo que a primeira apresenta a especificação do modelo econométrico a ser estimado para relacionar os efeitos da infraestrutura sobre a pobreza, seguida de uma subseção onde serão apresentados a fonte e o tratamento dos dados utilizados.

\subsection{MODELO ECONOMÉTRICO}

A abordagem econométrica é baseada em dados em painel estático para o período de 2015 a 2017, objetivando evidenciar os efeitos da infraestrutura sobre a pobreza em 850 municípios do estado de Minas Gerais ${ }^{3}$, resultando em uma amostra de 2550 observações.

3 O estado de Minas Gerais é composto por 853 municípios, entretanto, nesta amostra foram excluídos os municípios de Recreio, Rodeiro e São Francisco da Glória, devido a indisponibilidade de dados durante os anos analisados. 
Um painel de dados consiste em um arranjo entre séries temporais e dados em seção cruzada, apresentando duas dimensões de variação dos dados, a temporal e a espacial. A metodologia de dados em painel compreende o estudo de $n$ observações para dois ou mais períodos de tempo, possibilitando a disponibilidade de uma maior base de dados, o que contribui para aumento no número dos graus de liberdade e diminuição da colinearidade entre as variáveis explicativas. (DUARTE; LAMOUNIER; TAKAMATSU, 2008)

Gujarati e Porter (2011) confirmam essa ideia, apontando que a combinação de corte transversal e séries temporais, além de diminuir a colinearidade e aumentar o número de graus de liberdade como já descrito, gera dados mais informativos e com maior variabilidade.

Cabe ressaltar que para esta pesquisa, a estimação por painel dinâmico não é o método mais adequado. Isso se dá porque o número de observações temporais da análise é relativamente pequeno, logo os coeficientes estimados poderiam apresentar-se como viesados. Além disso, a estimação por painel dinâmico seria inconsistente visto que a heterogeneidade dos parâmetros entre os municípios mineiros e a presença de variáveis explicativas correlacionadas entre si induziria a um processo de correlação serial nos termos de erro.

O modelo geral para dados em painel é apresentado por:

$$
Y_{i t}=\beta_{0 i t}+\beta_{1 i t} X_{i t}+\cdots+\beta_{k i t} X_{k t}+\varepsilon_{i t}
$$

O subscrito $i$ corresponde aos distintos indivíduos (nesse caso, municípios do estado de Minas Gerais) e o subscrito $t$ indica o período de tempo em análise (2015 a 2017). Os parâmetros $\beta_{0}$ e $\beta_{k}$ correspondem ao intercepto e à k-ésima variável explicativa no modelo, respectivamente.

Existem três tipos de modelos a serem estimados por dados em painel estático, sendo eles: efeitos fixos, efeitos aleatórios e pooled. Para o exemplo de efeitos fixos, verifica-se o intercepto da regressão diferente entre os municípios do estado de Minas Gerais. Esse fato ocorre tomando a premissa de que cada município do estado, por mais que se encontrem na mesma unidade federativa, apresenta características singularmente próprias e que diferem entre as 
mesorregiões, por exemplo. Para verificar essa diferenciação são utilizadas variáveis dummies. A principal característica desse modelo diz respeito ao tratamento dados aos $\alpha_{i}$ 's como variáveis aleatórias não observadas e correlacionadas com algum $X_{i t}$. Assim sendo, a equação geral para a modelagem de efeitos fixos é apresentada por:

$$
Y_{i t}=\alpha_{i}+\beta X_{i t}+\varepsilon_{i t}
$$

Para o modelo de efeitos aleatórios, como a própria nomenclatura denota, os interceptos apresentam efeitos aleatórios, ou seja, desconsideram as particularidades de cada município mineiro, para o caso desta pesquisa. Cabe evidenciar que nesse modelo existe correlação em todas os lags, ou seja, este apresenta correlação com o seu erro.

A estimação de um modelo de efeitos aleatórios fundamenta-se a partir seguinte equação geral:

$$
Y_{i t}=\alpha_{i}+\beta X_{i t}+\mu_{i t}
$$

Por fim, em um modelo polled, os coeficientes são constantes entre as análises e ao longo do tempo, sendo estimado, geralmente, pela modelagem de Mínimos Quadrados Ordinários (MQO). O modelo recebe essa nomenclatura por apresentar-se como um modelo de agrupamento.

As estimativas por MQO apresentam algumas propriedades. Estas propriedades estão contidas no teorema de Gauss-Markov, que destaca a necessidade de o parâmetro apresentar-se como melhor estimador linear nãoviesado. O estimador de MQO é o melhor estimador linear não viesado (MELVN), caso apresente-se na forma linear, ou seja, uma função linear de uma variável aleatória, tal como a variável dependente do modelo de regressão. Logo, os estimadores serão:

i. Não viesados, ou seja, seus valores médios esperados são iguais aos valores verdadeiros;

ii. Apresentarão mínima variância mínima na classe de todos esses estimadores lineares não viesados; 
iii. Estimadores lineares não viesados e que apresentem as menores variâncias são conhecidos como estimadores eficientes (GUJARATI, 2011).

Vide a apresentação dos três modelos que podem ser utilizados para estimações com dados em painel estático, são realizados alguns testes para definição do modelo que se melhor se adequa à base de dados. Na sequência, a Figura 1 apresenta um organograma com os testes usualmente utilizados.

O primeiro teste a ser utilizado é o Teste de Chow, cuja hipótese nula considera o modelo pooled como sendo o melhor modelo, enquanto a hipótese alternativa considera o modelo de efeitos fixos. O segundo teste aplicado é o Teste de Hausman, que parte da hipótese nula de um modelo de efeitos aleatórios como o melhor a ser escolhido contra a hipótese alternativa de um efeito fixo. Por fim, é aplicado por último o Teste LM de Breusch-Pagan. A hipótese nula do modelo considera que a melhor adequação seria o modelo polled, contra a hipótese alternativa que julga o modelo fixo como o mais adequado. Logo, após a realização desses testes, determina-se o modelo mais adequado a ser estimado.

Figura 1 - Organograma dos testes para escolha do modelo mais adequado.

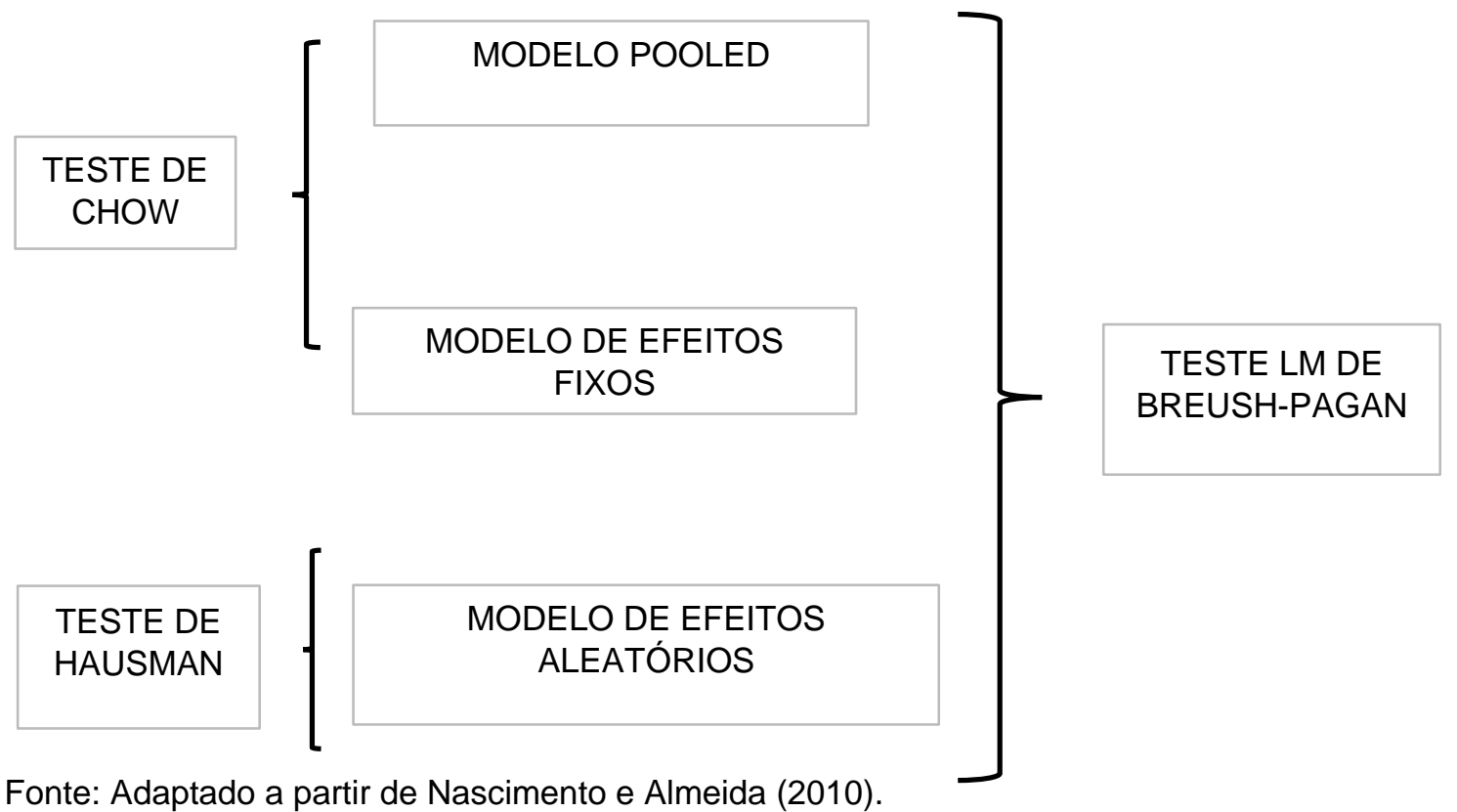

Dessa forma, após a apresentação das formas de modelagem e da escolha do modelo mais adequado, a forma funcional a ser estimada é a seguinte: 
lnb_fcadmeiosa $_{i t}{ }^{4}=\alpha_{i}+d_{-}$poppubr $_{i t}+r_{-}$emprsfajustdef $_{i t}+g_{-}$infradef $_{i t}+$ $b_{-}$pvulsaneacad $i t+g_{-} e d u c a c a o d e f_{i t}+g_{-} r l p c_{i t}+\varepsilon_{i t}$

Cabe destacar que a literatura que tange o tema, como apresentado nos aspectos teóricos e empíricos desta pesquisa, embasou a escolha das variáveis explicativas a serem utilizadas no modelo.

A variável utilizada como proxy para representar a pobreza nos municípios de Minas Gerais foi o log da taxa de famílias Cadastro único e com renda per capita de até meio salário mínimo por 100.000 habitantes, lnb_fcadmeiosa.

O procedimento para classificar a pobreza e a pobreza extrema, como retratado anteriormente na descrição das variáveis, foi pautado em uma análise quantitativa dos extratos de renda per capita dos indivíduos nos municípios analisados, entretanto, tem-se na literatura algumas críticas sobre a mensuração da pobreza única e exclusivamente através de dados quânticos.

Sen (1988) enfatiza a necessidade de focalizar a pobreza não somente através dos direitos sociais, assim como devem ser levados em consideração também os aspectos civis e políticos. Salama e Destremau (1999) destacam similarmente que um bom indicador de pobreza deve ter em vista os seus diversos aspectos, com o objetivo de proporcionar melhor entendimento da questão, e assim permitir a construção de um plano de ação eficiente no que diz respeito a esse considerável problema social.

Contudo, a disponibilidade de dados relativos a autopercepção dos indivíduos quanto à pobreza é ainda fortemente limitada (LOPES, MACEDO e MACHADO, 2005). Assim sendo, para a criação da variável utilizada como proxy para retratar a pobreza neste trabalho, levou-se em consideração o conceito de pobreza definido pelo Ministério de Desenvolvimento Social.

Como já ressaltado anteriormente, o objetivo geral desta pesquisa é verificar como investimentos em infraestrutura se relacionam com a pobreza no estado de Minas Gerais. Os gastos per capita em infraestrutura, g_infradef, neste trabalho,

\footnotetext{
${ }^{4}$ A consideração do logaritmo natural (In) da variável utilizada como proxy de pobreza teve como objetivo ajustar o modelo econométrico.
} 
representam esses investimentos dispendidos nos municípios mineiros defasados em 1 ano.

A variável consiste no valor dos gastos orçamentários apresentados nas prestações de contas anuais (PCA) realizados nas sub funções: Infraestrutura Urbana, Serviços Urbanos, Transportes Coletivos Urbanos, Comunicações Postais, Telecomunicações, Transporte Aéreo, Transporte Rodoviário, Transporte Ferroviário, Transporte Hidroviário e Transportes Especiais, dividido pela população total do município.

O resultado esperado é de relação inversa entre investimento em infraestrutura e pobreza, como retrata a literatura. Ferreira (1996) ressalta que o mecanismo é simples, sendo orientado pelo lado da oferta, ou seja, para uma quantidade de fatores de produção privados, uma maior dotação de equipamentos em infraestrutura (estradas, ferrovias, linhas de transmissão, saneamento) impulsiona o produto final e consequentemente aumenta a produtividade dos fatores privados, reduzindo o custo por unidade de insumo. $\mathrm{O}$ aumento da produtividade, por sua vez, induz um aumento da remuneração do capital fixo privado, alavancando novos investimentos e gerando novos postos de trabalho, logo, contribuindo para a diminuição da pobreza (ARAÚJO JÚNIOR, 2006).

Os gastos per capita com atividades de educação também defasados em 1 período, g_educacaodef, assim como retratado em algumas pesquisas, também se relacionam de forma inversa com a pobreza, ou seja, com mais investimentos em educação haveria redução na pobreza. Tal variável apresenta-se como valor dos gastos orçamentários apresentados nas prestações de contas anuais (PCA) realizados nas subfunções Ensino Fundamental, Ensino Médio, Ensino Profissional, Ensino Superior, Ensino Infantil, Educação de Jovens e Adultos e Educação Especial, dividido pela população total do município.

Os modelos de crescimento têm ressaltado a importância do estoque de capital humano para o crescimento econômico e, consequentemente, para a redução da pobreza. $O$ acesso a educação de boa qualidade, ou seja, a capacitação do capital humano, conduz os mais pobres a obterem melhor posição no mercado de trabalho e a romperem o ciclo da pobreza (ARAÚJO, CAMPELO e MARINHO, 2013). 
Cabe ressaltar que como mencionado, os referidos gastos em infraestrutura e educação foram defasados em 1 ano em função do tempo de maturação necessário para que seus efeitos ocorram sobre o nível de pobreza. Assim, para as referidas variáveis o período considerado é entre 2014 e 2016. Além disso, as duas variáveis são deflacionadas de acordo com Índice Nacional de Preços ao Consumidor (INPC).

A taxa de urbanização, d_poppubr, corresponde a razão entre o número total de pessoas residentes na área urbana do município e sua população residente total. Esta variável verifica como os índices de formação urbana podem se relacionar com a pobreza. A ideia que se tem nesta pesquisa é a de que comparativamente ao meio rural, encontram-se nas cidades menores índices de pobreza, devido a acessibilidade aos bens e serviços e maior aplicação de programas que objetivam reduzir a pobreza em meios urbanos.

A taxa de empregados no setor formal por 100.000 habitantes também defasada em 1 ano, emprsfajustdef, foi incluída como variável explicativa no modelo desta pesquisa. Trata-se mais especificamente da taxa de postos de trabalho, sendo que uma mesma pessoa pode ocupar mais de um posto. Espera-se de acordo com a literatura que esta variável se relacione de forma inversa à variável dependente, ou seja, um aumento da referida taxa ocasiona diminuição da pobreza. A ideia é que em função do aumento da renda per capita, advinda de novos salários, ocorra diminuição nos níveis de pobreza. Cabe ainda ressaltar que a defasagem de 1 ano teve como critério o fato de que existe um delay do efeito da taxa de emprego sobre o nível de pobreza.

O percentual de pessoas em vulnerabilidade pelas condições de saneamento básico no Cadastro Único, b_pvulsaneacad, é outra variável de controle dessa pesquisa. $O$ indicador refere-se à razão entre pessoas que tem como forma de abastecimento de água poço ou nascente, cisterna e outras formas, excluindo rede geral de distribuição; e forma de escoamento sanitário por fossa rudimentar, vala a céu aberto, direto para o rio ou lago e outra forma, excluindo rede coletora de esgoto ou pluvial e fossa séptica; e forma de coleta de lixo do tipo queimado ou enterrado na propriedade, jogado em terreno baldio ou logradouro (rua, avenida etc.), jogado em rio ou outro destino, excluindo o tipo de coleta direta e indireta; pelo total da população cadastrada no Cadastro Único. 
Torissi (2009) faz a distinção da infraestrutura em dois grupos infraestruturais, o econômico e o social. Investimentos em saneamento resultam em benefícios por parte desses dois grupos. Um aporte de investimento destinado a infraestrutura econômica, como a construção de rodovias, setores de saneamento, comunicações, áreas verdes e depósitos de lixo, pode beneficiar a população pobre no que concerne ao crescimento e desenvolvimento econômicos, enquanto os investimentos destinados a infraestrutura social se relacionam com o bem estar desse indivíduo, por questões de melhoria na acessibilidade e saúde, por exemplo.

A receita líquida per capita, $g_{-} r l p c$, também evidenciada no modelo e possui ligação estrita com a pobreza. A variável descreve a receita líquida per capita, calculada através do valor da receita orçamentária da administração municipal, deduzidas operações de crédito, dividido pela população total, em reais correntes Como o índice é calculado levando em consideração a receita do município, deduzido os valores de crédito e dividida pela população total, ela apresenta-se como um bom indicador a ser analisado. Cabe salientar que esta variável também foi deflacionada de acordo com Índice Nacional de Preços ao Consumidor (INPC).

Simão (2006) considera os rendimentos domiciliares per capita como os melhores indicadores para ajudar a sinalizar o nível de bem-estar de uma sociedade. Quanto maior o nível desses rendimentos em uma determinada região, mais desenvolvida ela tende ser, destaca o autor. Indicadores de bem-estar, assim como de crescimento e desenvolvimento, apresentam relação intrínseca com os níveis de pobreza. De acordo com o rendimento do município, também se pode concluir algo a respeito do status de pobreza daquela localidade. Ceteris Paribus, um aumento da receita líquida de uma localidade desencadeia diminuição na pobreza (IMRS, 2019).

\subsection{FONTE E TRATAMENTO DOS DADOS}

Todas as variáveis utilizadas nessa pesquisa foram retiradas do Índice Mineiro de Responsabilidade Social da Fundação João Pinheiro. O período analisado, 2015-2017, levou em consideração a disponibilidade de dados. 


\section{RESULTADOS}

Nesta seção, a princípio, é apresentada a análise descritiva das variáveis, e posteriormente são analisados os resultados econométricos obtidos com a estimação do modelo.

\subsection{ANÁLISE DESCRITIVA}

A análise descritiva das variáveis levou em consideração o período de análise do modelo econométrico, 2015-2017, com exceção das variáveis defasadas que contemplam o período 2014-2016.

De acordo com os resultados apresentados na Tabela 2, observa-se, através do desvio padrão da variável fcadmeiosa, elevada disparidade na taxa de famílias mineiras no Cadastro Único e com rendimentos de até meio salário mínimo. Isso decorre da discrepância entre máximos e mínimos da variável, o que pode ser explicado também pela desigualdade de renda presente no estado. Os municípios onde foram encontrados o máximo e o mínimo das taxas são Manhumirim, localizada na Zona da Mata mineira, e Nova Serrana, situada no Oeste do estado, respectivamente.

Domingues, Resende e Magalhães (2012) destacam a concentração da atividade econômica no estado de Minas Gerais, que está relacionado com o nível de pobreza. Nesse sentido, os autores afirmam que os gastos do governo, concentrados na região do Vale do Jequitinhonha/Mucuri e os investimentos mineradores alocados no Norte do estado, não são suficientes para gerar efeito desconcentrador.

$\mathrm{Na}$ sequência, os gastos per capita em infraestrutura defasados representam diretamente as desigualdades existentes entre os investimentos totais dispendidos pelos municípios mineiros. Essa observação é comprovada quando se atenta a elevada discrepância entre o mínimo e máximo dos referidos gastos nos municípios analisados, o que contribuiu para maior desigualdade de renda e acentuação dos níveis de pobreza em regiões onde se investe pouco em infraestrutura. 
Tabela 1 - Análise descritiva das variáveis

\begin{tabular}{|c|c|c|c|c|c|}
\hline Variável & $\begin{array}{c}\text { № de } \\
\text { Observações }\end{array}$ & Média & $\begin{array}{l}\text { Desvio } \\
\text { Padrão }\end{array}$ & Mínimo & Máximo \\
\hline $\begin{array}{l}\text { Taxa de famílias cadastradas no } \\
\text { Cadastro Único e com renda per } \\
\text { capita de até } 1 / 2 \text { salário mínimo } \\
\text { por } 100.000 \text { habitantes }\end{array}$ & 2550 & 13779,41 & 5018,62 & 2287,25 & 28742,48 \\
\hline $\begin{array}{c}\text { Gastos per capita em } \\
\text { infraestrutura defasados em } 1 \\
\text { ano }\end{array}$ & 2550 & 272,20 & 189,02 & 0 & 3732,91 \\
\hline Taxa de Urbanização & 2550 & 72,17 & 17,27 & 18,47 & 100 \\
\hline $\begin{array}{c}\text { Taxa de empregados no setor } \\
\text { formal por } 100.000 \text { habitantes } \\
\text { defasada em } 1 \text { ano }\end{array}$ & 2550 & 358,81 & 816,99 & 0 & 15346,59 \\
\hline $\begin{array}{c}\text { Percentual de pessoas em } \\
\text { situação de vulnerabilidade pelas } \\
\text { condições de saneamento pelo } \\
\text { Cadastro Único }\end{array}$ & 2550 & 0,85 & 1,03 & 0 & 8,8 \\
\hline $\begin{array}{c}\text { Gastos per capita em educação } \\
\text { defasados em } 1 \text { ano }\end{array}$ & 2550 & 614,64 & 259,91 & 0 & 3940,55 \\
\hline Receita líquida per capita & 2550 & 2614,00 & 1234,00 & 0 & 15996,86 \\
\hline
\end{tabular}

Fonte: Elaboração própria.

Nesse sentido, nos municípios e regiões onde a atividade econômica está concentrada, há menor necessidade de investimentos per capita em infraestrutura por parte do poder público, concentrando os gastos do governo em regiões de planejamento, como evidenciado por Domingues, Resende e Magalhães (2012).

Os gastos per capita em educação defasados seguem essa mesma tendência. Nos municípios onde esses investimentos são nulos, espera-se também acentuação na desigualdade social, o que impulsiona a pobreza e concentração de renda em determinadas regiões.

A receita líquida per capita também é um indicador coerente com os níveis de desigualdade mineiros. Nota-se um desvio padrão consideravelmente elevado para a variável, além também de diferença notável entre seu máximo e mínimo apresentados. Perobelii, Faria e Ferreira (2015) ressaltam a heterogeneidade espacial entre as mesorregiões brasileiras, evidenciando o exemplo do estado de Minas Gerais, onde segundo os autores, existem regiões muito ricas, detentoras de elevado PIB per capita e que concentram maiores indicadores de renda, o que corresponde ao resultado encontrado.

As variáveis "taxa de urbanização" e "taxa de empregados no setor formal por 100.000 habitantes" também apresentaram grande disparidade entre os seus valores máximos e mínimos. No caso da segunda variável, verifica-se grande 
divergência em relação às oportunidades no mercado de trabalho entre os municípios.

Por fim, o percentual de pessoas em situação de vulnerabilidade também se apresentou desigual nos municípios mineiros. Em determinados municípios, de acordo com os dados da amostra, não existem pessoas que se enquadram nessa situação, enquanto em outros aproximadamente $8,8 \%$ da população está em situação de vulnerabilidade. Minas Gerais ainda possui trinta municípios em situação de extrema pobreza e vulnerabilidade, todos localizados no Vale do Jequitinhonha e Mucuri. Não se trata somente da ausência de recursos monetários, mas de problemas nas áreas de habitação, saúde, educação, saneamento, entre outros; que evidenciam as disparidades regionais ainda não superadas (RAMOS, 2015).

Como o objetivo primordial do presente estudo é analisar o efeito dos gastos em infraestrutura defasados sobre a taxa de famílias no Cadastro único e com renda per capita de até meio salário mínimo por 100.000 habitantes, proxy do nível de pobreza considerada para o estado de Minas Gerais, o Gráfico 1 ilustra essa relação. Para a construção da Gráfico, os municípios mineiros foram agrupados em suas respectivas mesorregiões, devido ao grande número de observações quando se considera os municípios individualmente.

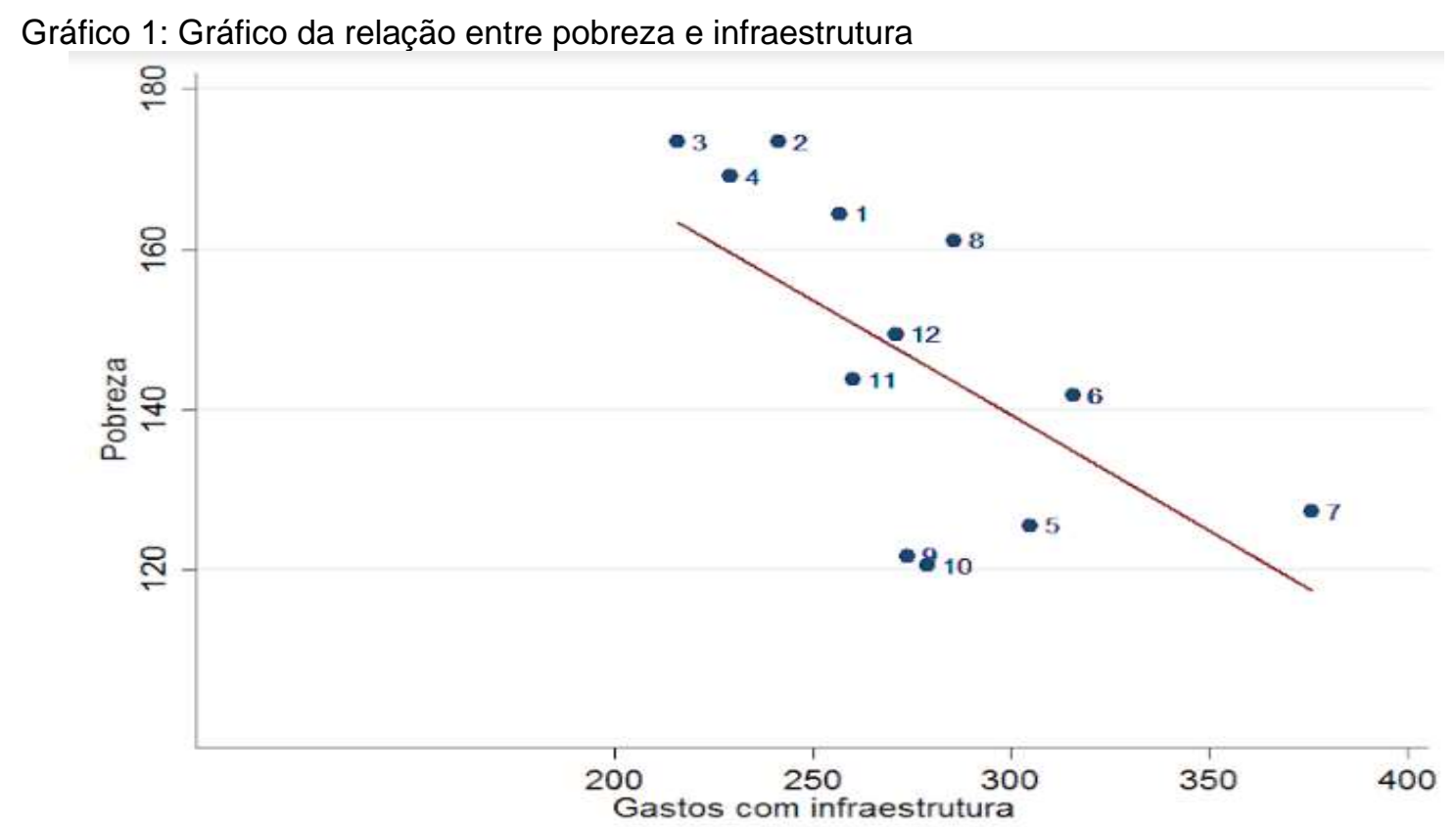

Fonte: Elaboração própria. 
Inicialmente, é possível observar uma linha de tendência que evidencia a relação inversa entre os referidos gastos e a pobreza nas mesorregiões mineiras ${ }^{5}$, o que vai ao encontro da literatura que concerne a temática. Além disso, cabe destacar o caso das mesorregiões do Norte de Minas, Vale do Jequitinhonha e Mucuri. Além de apresentarem elevados índices de pobreza, como observado no Gráfico, essas mesorregiões encontram-se fora da linha de tendência dos gastos em infraestrutura, evidenciando-se, assim, a necessidade de intensificação infraestrutural nessas regiões.

Em Minas Gerais, a Ação de Apoio a Projetos de Infraestrutura - PROINF, criada em 2003, alocou recursos nas áreas de infraestrutura nessas regiões do estado. Do total de recursos empregados em Minas Gerais no ano de 2016, 29\% foram alocados nos territórios do Alto e Médio Jequitinhonha. Entretanto, no Baixo Jequitinhonha, os investimentos não foram realizados, devido às dificuldades de organização e captação de recursos, denotando os grandes problemas de gestão nas regiões (BATISTA, et.al, 2016).

\subsection{RESULTADOS ECONOMÉTRICOS}

A princípio, foram realizados alguns testes para verificar qual o modelo mais adequado para a estimação (efeitos fixos, efeitos aleatórios ou pooled). Inicialmente, como apresentado no organograma da Figura 1, foi realizado o Teste de Chow, que apontou preferencialmente para um modelo de efeitos fixos ao invés do pooled. Posteriormente, foi aplicado o Teste de Hausman, que reafirmou a preferência para uma estimação em efeitos fixos no modelo. Logo, o modelo a ser estimado é de efeitos fixos para dados em painel estático.

Além disso, através do teste de White, aplicado em sequência, verificou-se a presença de heterocedasticidade no modelo. O problema foi corrigido através da estimação que considera os erros padrões robustos. Para detectar a existência ou não de multicolinearidade entre as variáveis explicativas, foi realizado também o

\footnotetext{
${ }^{5}$ Para elaboração do gráfico, as mesorregiões mineiras foram classificadas em ordem numérica, resultando na seguinte legenda: Noroeste de Minas (1); Norte de Minas (2); Jequitinhonha (3); Vale do Mucuri (4); Triângulo Mineiro/Alto Paraopeba (5); Central Mineira (6); Metropolitana de Belo Horizonte (7); Vale do Rio Doce (8); Oeste de Minas (9); Sul/Sudoeste de Minas (10); Campo das Vertentes (11); Zona da Mata (12).
} 
teste do fator de inflacionamento da variância (VIF), que detectou a inexistência de multicolinearidade no modelo. Assim, o resultado da estimação do modelo econométrico encontra-se na Tabela 3.

Tabela 3 - Resultados da estimação do modelo econométrico

\begin{tabular}{|c|c|}
\hline Variável & Coeficiente \\
\hline \multirow{2}{*}{ d_popurb } & $-0,0001128^{*}$ \\
\hline & $(0,000681)$ \\
\hline \multirow{2}{*}{ r_emprsfajustdef } & $0,0012784^{* * *}$ \\
\hline & $(0,003794)$ \\
\hline \multirow{2}{*}{ g_infradef } & $-0,000407^{\star *}$ \\
\hline & $(0,000019)$ \\
\hline \multirow{2}{*}{ b_pvulsaneacad } & $0,0315987^{* * *}$ \\
\hline & $(0,0062841)$ \\
\hline \multirow{2}{*}{ g_educacaodef } & $-0,0000512^{\star *}$ \\
\hline & $(0,0000271)$ \\
\hline \multirow{2}{*}{ g_rlpc } & $-0,0000836^{\star * *}$ \\
\hline & $(0,0000175)$ \\
\hline \multirow{2}{*}{ Constante } & $5.089 .674^{* * *}$ \\
\hline & $(0,0432658)$ \\
\hline
\end{tabular}

Fonte: Elaboração própria.

Nota: ${ }^{* *}$ Significativo ao nível de 1\%; ** Significativo ao nível de 5\%; ${ }^{*}$ Significativo de $10 \%$. Os valores entre parênteses são os desvios padrão.

Como o objetivo principal desta pesquisa é analisar de que forma a infraestrutura se relaciona com a pobreza nos municípios do estado de Minas Gerais, evidencia-se o coeficiente estimado para a variável g_infradef. O resultado esperado e encontrado nesta pesquisa é de relação inversa entre gastos em infraestrutura e pobreza, como retrata a literatura. Este resultado confirma a ideia de que investimentos em infraestrutura contribuem para a diminuição da pobreza, atentando-se ao tempo de maturação de 1 ano para que esses gastos exerçam influência sobre a pobreza.

Araújo, Campelo e Marinho (2013) destacaram o efeito que a infraestrutura exerce sobre a redução da pobreza, o que indica que investimentos em infraestrutura influenciam diretamente a trajetória temporal da pobreza no Brasil, no sentido de reverter esse quadro. Nesse sentido, Cruz, Teixeira e Braga (2010) demostraram a eficiência das despesas públicas em educação e saúde, bem como em gastos infra estruturais quanto à melhoria do capital humano e físico no país. 
Esses fatores, conjuntamente, afetam de forma positiva o rendimento per capita e a produtividade na economia.

Assim, sob outra ótica, os investimentos em infraestrutura contribuem também para o desenvolvimento, através do aumento da produtividade dos fatores e de amenidades que melhoram a qualidade de vida dos indivíduos (ARAÚJO JÚNIOR, 2006). Logo, como demonstrado ao longo desta pesquisa, nos municípios ou regiões mineiras onde mais se gasta com infraestrutura se encontram os melhores indicadores sociais e econômicos, e consequentemente menores indicadores de pobreza. Consequentemente, o aporte de gastos destinado a infraestrutura nessas localidades melhoraria o capital físico (ferrovias, pavimentação, saneamento e etc), impulsionaria o desenvolvimento, melhorando os indicadores sociais através de elevações na renda per capita advindos de maior produtividade.

Analisando-se a variável b_vulsaneacad, observa-se que ela apresentou sinal positivo e também foi estatisticamente significativa ao nível de 1\%. Mensurações sobre índices de vulnerabilidade são um problema nas bases de dados brasileira. Como já explicado na descrição das variáveis, o percentual de pessoas em situação de vulnerabilidade foi construído levando em consideração o número de famílias que possuem privações em diversos aspectos de saneamento, habitação e acesso, divididos pela população total. Logo, esse percentual apresenta impacto positivo sobre a pobreza, contribuindo para as disparidades socioeconômicas entre os municípios, assim como verificado no modelo econométrico.

Em relação a variável $r$ _emprsfajustdef, o sinal positivo evidenciado no modelo econométrico, com sua significância a $1 \%$, resultou em uma conclusão contrária a esperada, de que um aumento na taxa de empregados no setor formal por 100.000 habitantes defasada em 1 ano contribuiria para aumentar a pobreza.

Uma possível explicação para esse resultado se baseia na desigualdade de renda. Barbosa (2017) evidenciou que as diferenças de renda aumentaram entre os que estão na base e no topo das pirâmides dos ganhos. Dessa forma, um aumento na taxa de empregos no setor formal não impactaria ou contribuiria positivamente com a pobreza, devido ao fato dessas vagas se encontrarem concentradas em determinadas regiões e classes sociais. Analisando-se os resultados encontrados, o número de empregos no setor formal concentra renda e não diminui a pobreza, 
cabendo ao setor informal a capacidade de impactar nesses indicadores sociais de paupérie.

As variáveis de taxa de urbanização, gastos em educação defasados e receita líquida per capita apresentaram sinal negativo esperado, com níveis de significância de 1,5 e 10\%, respectivamente. Esses resultados demonstram a capacidade dessas variáveis em impactar negativamente sobre a pobreza.

Nesse sentido, a relação inversa entre urbanização e pobreza pode ser explicada levando em consideração o trabalho de Costa e Costa (2016), que evidenciam o fato de políticas de combate à pobreza serem desiguais entre regiões urbanas e rurais. Em áreas rurais, é mais difícil a implementação e aderência dessas políticas, o que demonstra que mesmo com as disparidades sociais presentes em áreas urbanas, são nestas onde se obtém maior efeito sobre a pobreza, com programas que visem sua diminuição.

Com relação ao coeficiente estimado positivo para a variável de gastos com educação defasados em 1 ano, Vespúcio (2010) destaca que o investimento em capital humano, por meio da educação, corrige as desigualdades sociais e reduz a pobreza.

Por fim, como supracitado, a variável de receita liquida per capita, g_rlpc, também apresentou relação contrária à pobreza. A variável captura a condição de renda do município e vai ao encontro da literatura, apontando que elevações na renda per capita diminuem a pobreza. Nesse sentido, Programas de transferência de renda condicionados e aporte de ativos financeiros, como programas de microcréditos, podem ser de grande importância para a redução da pobreza (ASSIS; MEDEIROS; NOGUEIRA; 2006).

\section{CONSIDERAÇÕES FINAIS}

Considerando a grande discussão sobre mecanismos capazes de diminuir a pobreza no Brasil como um todo, neste trabalho objetivou-se compreender de que forma a infraestrutura poderia reduzi-la especificamente nos municípios do estado de Minas Gerais. Para tal, foram utilizados dados de 2015 a 2017 para os municípios mineiros, a fim de estimar o modelo econométrico em painel estático por efeitos fixos. 
O principal resultado denotou que os gastos em infraestrutura defasados em 1 ano reduzem a taxa de famílias no Cadastro Único e com renda per capita de até meio salário mínimo por 100.000 habitantes, utilizada como proxy para representar a pobreza no estado.

Os aportes destinados a infraestrutura nos municípios mineiros reduzem a pobreza através do aumento da quantidade de capital físico (ferrovias, saneamento, telecomunicações e etc) com concomitante elevação da produtividade, o que impulsiona o processo de desenvolvimento econômico, vide melhoria dos indicadores sociais, tendo como cerne fundamental a diminuição da pobreza.

Logo, a partir dos resultados encontrados, espera-se contribuir com a formulação de políticas públicas que reduzam a pobreza em Minas Gerais, através dos investimentos em infraestrutura. Além dos investimentos em si, torna-se essencial a eficiência na gestão pública dos recursos para que se tenha o impacto esperado sobre a diminuição da pobreza.

\section{REFERÊNCIAS}

ARAÚJO JÚNIOR, I. T. de; Investimentos em infraestrutura e crescimento econômico no Brasil - Economia e Desenvolvimento, Universidade Federal da Paraíba, v. 5, n. 2, p161-188, 2006, Recife (PE).

ARAÚJO, J.; CAMPELO, G.; MARINHO, E. Os impactos da infraestrutura sobre a pobreza para o Brasil. Associação Nacional dos Centros de Pós-graduação em economia (Brasil), ANPEC. Rio de Janeiro, 2013.

ASCHAUER, D. A. Is public expenditure productive? Journal of Monetary

Economics, v. 23, n. 2, p. 177-200, Mar. 1989. Disponível em: < https://fraser.stlouisfed.org/files/docs/historical/frbchi/workingpapers/frbchi_workingpa per_1988-10.pdf >. Acesso em: 30 out. 2019.

Assis, D. N. C.; Medeiros, C. N.; Nogueira, C. A. G. Extrema pobreza infantil, crescimento e distribuição de renda. Planejamento e Políticas Públicas, n. 48, p. 175-210, jan./jun. 2017.

BALISACAN, A. M.; PERNIA, E. M. Probing Beneath Cross- National Averages: Poverty, Inequality, and Growth in the Philippines, ERD Working Paper Series, n. 7, Economics and Research Department, Asian Development Bank, Manila, 2002. 
BALISCAN, A.M; PERNIA, E. D e ASRA, A. Revisitando o crescimento e a redução da pobreza na Indonésia: o que mostram os dados subnacionais? Indonésia, 2003.

BÁRCENA, A. et.al. Desarrollo social inclusivo: una nueva generación de políticas para superar la pobreza y reducir la desigualdad en América Latina y el Caribe. In: CONFERENCIA REGIONAL SOBRE DESARROLLO SOCIAL DE AMÉRICA LATINA Y EL CARIBE, 2015, Lima. CEPAL...Santiago, Naciones Unidas, 2016.

BATISTA, A. M. A et. al. Território e Infraestrutura no Vale do Jequitinhonha, uma análise do PROINF entre 2003 e 2014. Cedeplar Diamantina, 2016.

BID - BANCO INTERAMERICANO DE DESENVOLVIMENTO. Relatório anual, vários números.

CAMPOS NETO, C. A. S.; CONCEIÇÃO, J. C. P. R.; ROMMINGER, A. E. Impacto da Infraestrutura de Transportes sobre o Desenvolvimento e a Produtividade no Brasil. In: DE NEGRI, F.; CAVALCANTE, R. (Org). Produtividade no Brasil: desempenho e determinantes, v. 2, 1 ed. Brasília: IPEA:ABDI, 2015. p. 361-390.

COSTA, R; F; R. COSTA; G.; C. Pobres no campo, ricos na cidade? Uma análise multidimensional da pobreza. Rev. Econ. Sociol. Rural vol.54 no.3 Brasília jul/ set. 2016.

CRUZ, A. C; TEIXEIRA, E. C; BRAGA, M. J. Os efeitos dos gastos públicos em infraestrutura e em capital humano no crescimento econômico e na redução da pobreza no Brasil. Economia, Selecta, Brasília (DF), v.11, p.163-185, dez. 2010.

DERCON, S; KRISHNAN, P. Vulnerabilidade, sazonalidade e pobreza na Etiópia. The Journal of Development Studies, v. 36, n. 6, p. 25-53, 2000. DOMINGUES, E. P; RESENDE, M.F.da Cunha; MAGALHÃES, A.S. Crescimento e desigualdade regional em Minas Gerais: uma avaliação para o período 20122030. Cedeplar UFMG. 2012.

DUARTE, P. C.; LAMOUNIER, W. M.; TAKAMATSU, R. T. Modelos Econométricos para Dados em Painel: Aspectos Teóricos e Exemplos de Aplicação à Pesquisa em Contabilidade e Finanças. Tópicos de Ensino e Pesquisa. São Paulo: Atlas, 2008.

ESCOBAL, J.; SAAVEDRA, J.; TORERO, M. Los activos de los pobres en el Perú. Lima: GRADE. 57 p. Documento de trabajo, 26, 1999.

EVANGELISTA; O. SHIROMA; E. O. Educação para alívio da pobreza: novo tópico na agenda global. Revista de educação PUC - Campinas, n.20, p.43-54, junho 2006. 
FERREIRA, P. C. Investimento em infraestrutura e no Brasil: fatos estilizados e relações de longo prazo. Pesquisa e planejamento Econômico (PPE), Rio de Janeiro, v.26, n. 2, p.231-252, 1996.

FERREIRA, S. N.D. Qualidade da infraestrutura de transporte rodoviário e desenvolvimento econômico no Brasil. Monografia apresentada ao Departamento de Economia da Universidade Federal de Viçosa como parte das exigências para obtenção do título de Bacharel em Ciências Econômicas. Viçosa, MG. 2018.

GIBSON, J; ROZELLE, S. Poverty and Access to Roads in Papua New Guinea. Economic Development and Cultural Change 52(1): 159-185, 2003.

GUIMARÃES, N.A et al. Os pores e o estado. Entre a ação pública e o interesse privado. Revista Novos Estudos. CEBRAP, São Paulo. v.36.02, São Paulo, SP. 2017.

GUJARATI, D. N; PORTER, D. C. Econometria Básica-5. AMGH Editora, 2011.

IMRS - Índice Mineiro de Responsabilidade Social. Fundação João Pinheiro. Belo Horizonte, 2019. Disponível em: < http://imrs.fjp.mg.gov.br/>. Acesso em. 10 nov. 2019.

JACOBY, $\mathrm{H}$. Access to markets and the benefits of rural roads. Economic Journal, v.110, p.713- 737, 1998.

KAGEYAMA, A.; HOFFMANN, R. Pobreza no Brasil: Uma Perspectiva Multidimensional. Economia e Sociedade, Campinas, v.15, n.1(26), p.79-112, jan./jun. 2006.

LOPES, H. M.; MACEDO, P. B. R.; MACHADO, A. F. Análise de pobreza com indicadores multidimensionais para o Brasil e Minas Gerais. Technical report, CEDEPLAR, 2004.

MAIA, M. S. Efeitos da infraestrutura de transporte sobre o crescimento econômico brasileiro de 2001 a 2012. Dissertação apresentada a Universidade Federal de Viçosa, como parte das exigências do Programa de Pós-Graduação em Economia, para o título de Magister Scientiae. Viçosa, MG. 2015.

MEDEIROS, M; BARBOSA, R. J; CARVALHES, F. Texto para discussão / Instituto de Pesquisa Econômica Aplicada. - Brasília: Rio de Janeiro: Ipea, 2019.

MEDEIROS, V.; RIBEIRO, R. S. M. Investimento em infraestrutura: uma estrada para o desenvolvimento. Santiago: Comissão Econômica para a América Latina e o Caribe (CEPAL), 2019 (Publicação das Nações Unidas).

MELLO, J. Estratégias de superação da pobreza no Brasil e impactos no meio rural. Rio de Janeiro: IPEA, 2018. 
NASCIMENTO, A. C. C.; ALMEIDA, F. M. de. Universidade Federal de Viçosa. Centro de Ciências Agrárias. Departamento de Economia Rural. Aula Prática № 3 “Dados em Painel”. 2010.

OGUN, T. P. Infrastructure and Poverty Reduction - Implications for Urban Development in Nigeria”. UNU-WINDER Working Paper, n. 43, mar. 2010.

PEROBELLI, F. S.; FERREIRA, P. G. C.; FARIA, W. R. Análise de convergência espacial no estado de Minas Gerais: 1975-2003. Revista Brasileira de Estudos Regionais e Urbanos, v. 1, n. 1, 3 fev. 2015.

QUEIROZ, B. L. Diferenciais de salários nas microrregiões mineiras. Belo Horizonte. 2001. 191 p. Dissertação. Faculdade de Ciências Econômicas Universidade Federal de Minas Gerais.

RAJKUMAR, A.S. and SWAROOP, V. Public Spending and Outcomes: Does Governance Matter? Journal of Development Economics, 86, 96-111. http://dx.doi.org/10.1016/j.jdeveco.2007.08.003, 2008.

RAMOS, L. Desigualdade de rendimentos do trabalho no Brasil de 1995 a 2005. In BARROS, R. P.; FOGUEL, M. N.; ULYSSEA, G. (orgs.). Desigualdade de renda no Brasil: uma análise da queda recente. Brasília: IPEA, vol. 2, p.267-284, 2007. Disponível em: <http://ipea.gov.br/agencia/images/stories/PDFs/mercadodetrabalho/mt_30d.pdf>. Acesso em: 6 de novembro de 2019.

ROY, K. Effect on public infrastructure on poverty reduction in India: a state level study for the period 1981-2001. Indian Journal of Milenium Development studies: an international journal, v. 4, n. 1, p. 99-111, mar. 2009.

RUNSINARITH, P. Infrastructure Development and Poverty Reduction: Evidence from Cambodia's Border Provinces. Graduate School of International Studies. Nagoya University, 2008.

SALAMA, P.; DESTREMAU, B. O tamanho da pobreza: economia política da distribuição de renda. Rio de Janeiro: Garamond, 1999. 160p.

SANTOS, A.C; GOMES, A.P; ERVILHA, G.T. Eficiência e desigualdade em educação no estado de Minas Gerais: Uma análise da primeira etapa do PMDI. Revista de planejamento e políticas públicas (ppp), n. 35, jul/dez. 2015. Viçosa, MG.

SEETANAH, B; RAMESSUR, S; ROJID, S. Does Infraestructure Alleviates Poverty in Developing Countries? International Journal of Applied Econometrics and Quantitative Studies, v. 6, p. 2, 2009.

SEN, A. The concept of development. In: CHENERY, H., SRINIVASAN, T.N. (Eds.) Handbook of development economics. Amsterdan: Elsevier Science, 1988. v.1, p.926. 
SILVA, A. de A. P. et al. Educação em Minas Gerais: Uma Análise de Eficiência na Alocação de Recursos Públicos - Título do Artigo. Dissertação (Mestrado) Universidade Federal de Viçosa, Viçosa, MG, 2009.

TORRISI, Gianpiero. Public infrastructure: definition, classification and measurement issues. Economics, Management, and Financial Markets, n. 3, p. 100-124, 2009.

VESPÚCIO, Euler. Educação diminui a pobreza. Disponível em: <https://www.ultimasnoticias.inf.br/noticia/educacao-diminui-a-pobreza/>, acesso em 14 de novembro de 2019

Recebido em: abril de 2020

Aceito em: maio 2020 